OPEN ACCESS

Edited by:

Kenji Hashimoto,

Chiba University, Japan

Reviewed by:

Tianmei Si,

Peking University Sixth Hospital, China

Yilang Tang,

Emory University, United States

*Correspondence:

Glen B. Baker

glen.baker@ualberta.ca

Specialty section:

This article was submitted to

Molecular Psychiatry,

a section of the journal

Frontiers in Psychiatry

Received: 28 October 2018 Accepted: 15 January 2019 Published: 06 February 2019

Citation:

MacKay M-AB, Kravtsenyuk $M$,

Thomas R, Mitchell ND, Dursun SM and Baker GB (2019) D-Serine:

Potential Therapeutic Agent and/or

Biomarker in Schizophrenia and

Depression? Front. Psychiatry 10:25.

doi: 10.3389/fpsyt.2019.00025

\section{D-Serine: Potential Therapeutic Agent and/or Biomarker in Schizophrenia and Depression?}

\author{
Mary-Anne B. MacKay ${ }^{1,2}$, Maryana Kravtsenyuk ${ }^{1,2}$, Rejish Thomas ${ }^{1}$, \\ Nicholas D. Mitchell ${ }^{1,2}$, Serdar M. Dursun ${ }^{1,2}$ and Glen B. Baker ${ }^{1,2 *}$ \\ ${ }^{1}$ Neurochemical Research Unit and Bebensee Schizophrenia Research Unit, Department of Psychiatry, University of Alberta, \\ Edmonton, AB, Canada, ${ }^{2}$ Neuroscience and Mental Health Institute, University of Alberta, Edmonton, AB, Canada
}

D-Serine is a potent co-agonist at the NMDA glutamate receptor and has been the object of many preclinical studies to ascertain the nature of its metabolism, its regional and cellular distribution in the brain, its physiological functions and its possible clinical relevance. The enzymes involved in its formation and catabolism are serine racemase (SR) and D-amino acid oxidase (DAAO), respectively, and manipulations of the activity of those enzymes have been useful in developing animal models of schizophrenia and in providing clues to the development of potential new antipsychotic strategies. Clinical studies have been conducted in schizophrenia patients to evaluate body fluid levels of D-serine and/or to use D-serine alone or in combination with antipsychotics to determine its effectiveness as a therapeutic agent. D-serine has also been used in combination with DAAO inhibitors in preclinical investigations, and interesting results have been obtained. Genetic studies and postmortem brain studies have also been conducted on D-serine and the enzymes involved in its metabolism. It is also of considerable interest that in recent years clinical and preclinical investigations have suggested that D-serine may also have antidepressant properties. Clinical studies have also shown that D-serine may be a biomarker for antidepressant response to ketamine. Relevant to both schizophrenia and depression, preclinical and clinical studies with D-serine indicate that it may be effective in reducing cognitive dysfunction.

Keywords: D-serine, D-amino acids, schizophrenia, depression, serine racemase, D-amino acid oxidase

\section{INTRODUCTION}

Several amino acids have a chiral center and thus can exist as D- and L-isomers. For many years, it was thought that only the L-isomers of these amino acids existed in mammalian tissue. However, it was discovered in the 1990s that relatively large quantities of free D-serine exist in the mammalian brain (1-3), although at lower concentrations than L-serine (1-5). Free D-aspartate and D-alanine (Figure 1) are also present in brain at levels much lower than those of D-serine and of their respective L-isomers, but still measureable $(2,3,5,7-13)$. Interestingly, it has been reported that all three of these D-amino acids may contribute to brain function (14-22) and may be useful as adjuncts in the therapy of schizophrenia $(4,7,10,17,20-22)$.

The focus of this review is on D-serine and its possible involvement with both schizophrenia and depression. D-Serine is a potent coagonist at the N-methyl-D-aspartate (NMDA) glutamate receptor and appears to have a major modulatory role in NMDA receptor-mediated neurotransmission, neurotoxicity, synaptic plasticity, and cell migration $(5,8,15,18-23)$. 


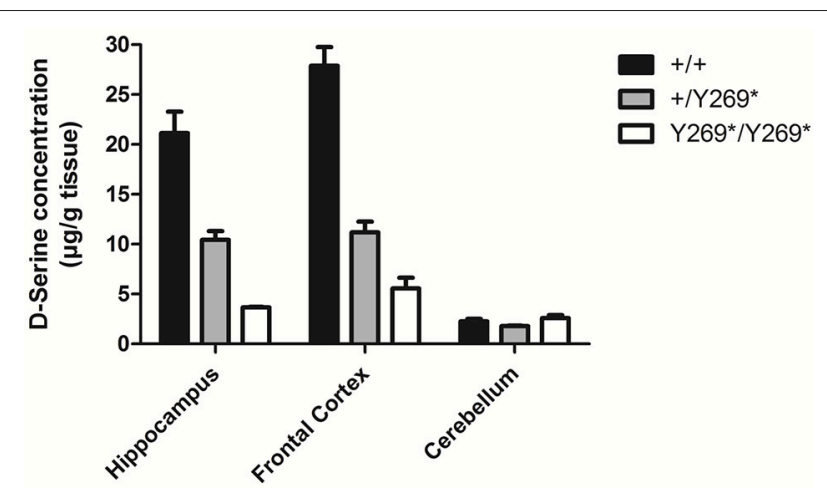

FIGURE 1 | Levels of D-serine in frontal cortex, hippocampus and cerebellum in mice with a nonsense mutation of exon 9 of the gene for SR: wild type, $(+/+)$, heterozygous $\left(+/ Y 269^{*}\right)$, and mutant $\left(Y 269^{*} / Y 269^{*}\right)$ mice. Behavioral deficits (impairment in prepulse inhibition, sociability, and spatial discrimination) in the mutant mice were worsened by an NMDA receptor antagonist and ameliorated by D-serine or clozapine [adapted from Labrie et al. (6)].

Considerable research now indicates that it may be a potential therapeutic agent and/or biomarker in both schizophrenia and major depressive disorder, as will be discussed in this review paper.

\section{METHODS}

Searches were done in PubMed and Web of Science covering the period 1990-2018 and the key phrases "D-serine and neuropsychiatric disorders," D-serine and schizophrenia," "Dserine and depression," "D-amino acids in neuropsychiatric disorders," and "D-serine and ketamine" were used in the searches. Only papers in English were used in the preparation of this review. The references obtained were screened by the authors to determine which would be best to put in this paper.

\section{D-SERINE AS A POSSIBLE BIOMARKER AND/OR THERAPEUTIC AGENT IN SCHIZOPHRENIA}

There is now a large body of evidence supporting hypofunction of NMDA glutamate receptors in schizophrenia (24-27). Because $\mathrm{D}$-serine is such a potent coagonist at the NMDA receptor, there has been a great deal of interest in its role in the brain. $\mathrm{D}$-Serine is present in glia (mainly astrocytes) and neurons. It has been proposed as both a glial transmitter $(28,29)$ and a neurotransmitter (30), and this has resulted in considerable controversy [see $(29,30)$ for an interesting discussion of the relevant importance of glia and neurons in the actions of D-serine]. Wolosker etal. (30) have proposed that astrocytes synthesize L-serine which then shuttles to neurons to be converted to $\mathrm{D}$-serine.

The NMDA glutamate receptor requires not only glutamate but a coagonist in order to be activated. For many years, it was thought that glycine was the coagonist and the site at which it acts on the NMDA receptor is termed the glycine binding site. There is now considerable evidence, including a regional distribution more closely resembling that of NMDA receptors than is the case with glycine (4) and a stronger affinity than glycine for the glycine binding site on the NR1 subunit of the NMDA receptor $(31,32)$, indicating that $\mathrm{D}$-serine may be more important in this regard. Because of the large body of evidence indicating hypofunctioning of the NMDA glutamate receptor in schizophrenia, D-serine has become of great interest to many researchers, and it has been proposed as the primary NMDA receptor coagonist in the forebrain and hippocampus (14). Glycine and D-serine appear to act at different NMDA receptor populations, D-serine at synaptic receptors and glycine at extrasynaptic receptors (33). It has been proposed that synaptic NMDA receptors are neuroprotective and that extrasynaptic receptors may promote cell death (34).

A number of preclinical studies in rodents have demonstrated that lowering brain levels of D-serine by reducing the activity of serine racemase (SR), the enzyme responsible for catalyzing formation of D-serine from L-serine (e.g., Figure 1), can produce symptoms reminiscent of clinical symptoms in schizophrenia: stereotypies, cognitive deficits, disruption of prepulse inhibition (measure of sensorimotor gating), persistent latent inhibition (measures inhibitory learning and cognitive flexibility), and deficits in social interaction $(6,19-22,35)$. It has also been reported that SR knockout mice show a reduction of basal NMDA receptor activity and reduced arborization and spine density in dendrites (36). Chronic D-serine reverses expression of activityrelated cytoskeleton-associated protein (Arc) and causes partial rescue of dendritic abnormalities in the same model (36).

Spatial and reversal memory deficits in Sprague-Dawley rats treated with the NMDA receptor antagonist phencyclidine (PCP) at different developmental stages can be reversed with $\mathrm{D}$ serine administration (37). Hagiwara etal. (38) conducted an experiment with SR-inhibited mice where $\mathrm{D}$-serine was given as a supplement in the preadolescent phase, and this had some benefit in preventing adult onset psychosis, suggesting the possibility of using D-serine supplementation in early intervention in humans. Fujita etal. (39) reported that juvenile and adolescent rodents that had been exposed prenatally to maternal immune activation showed reduced expression of hippocampal NMDA receptor subunits and onset of cognitive deficits as adults; supplementing their drinking water with D-serine from P28 to P56 reduced cognitive deficits.

For further information about SR and D-amino acid oxidase (DAAO), see the next section.

\section{FORMATION AND CATABOLISM OF D-SERINE AND RELEVANCE OF THIS METABOLISM TO SCHIZOPHRENIA}

D-Serine formation from L-serine is catalyzed via the enzyme SR and its catabolism is catalyzed by DAAO (40-46) (Figure 2).

In the brain, SR and D-serine are found in the same regions, i.e., high levels in forebrain areas such as cortex and hippocampus and very much lower levels in the cerebellum and brain stem (35). Activity of SR can be modulated through various $\quad \alpha$-amino-3-hydroxy-5-methylisoxazole-4-propionic 


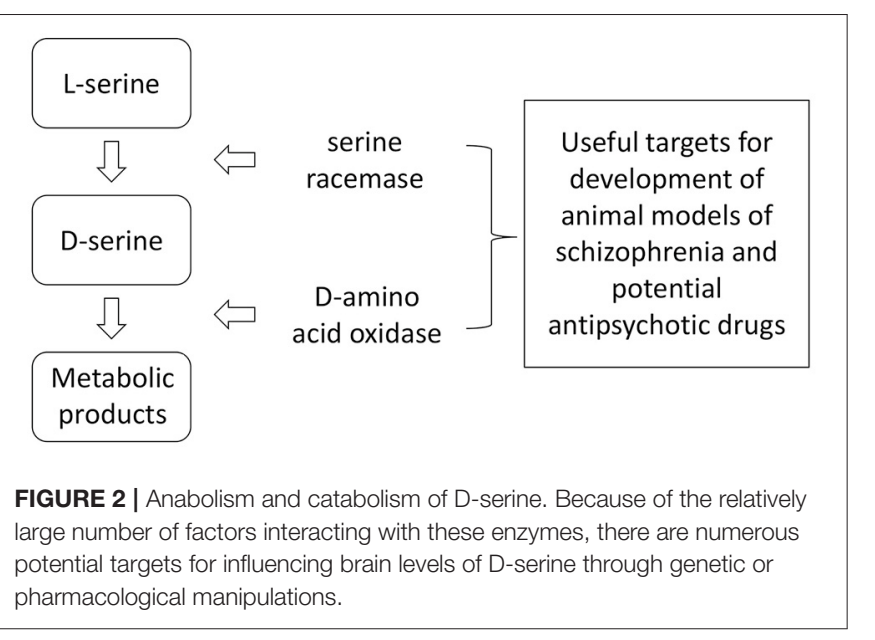

acid (AMPA) receptor-dependent, metabotropic mGluR2/3/5 receptor-dependent mechanisms, divalent cations and the adenosine triphosphate (ATP) pathway, suggesting potential targets by which D-serine concentrations could be enhanced (47-49). AMPA-induced postsynaptic membrane depolarization builds up intracellular calcium concentrations and stimulates SR with the soluble N-ethylmaleimide-sensitive factor attachment protein receptor (SNARE) (48). Ma etal. (50) reported SR interactions with stargazin and the scaffolding protein PSD-95 and suggested that these proteins regulate NMDA receptorAMPA receptor cross-talk in neurons. Lin etal. (51) proposed an association of D-serine with PSD-95 and NMDA receptors in postsynaptic neurons and with stability of glutamatergic synapses during development of cortical synapses. Glutamate-receptorinteracting-protein (GRIP) forms a complex with mGluR2/3 receptors, and receptor activation changes the conformation of SR, altering its function and decreasing production of D-serine (49).

Single nucleotide polymorphisms in the gene encoding protein interacting with C-kinase 1 (PICK1), a component of protein kinase $\mathrm{C}$ signaling, have been reported to be associated with a higher risk of schizophrenia, and it has been suggested that this link could be mediated through the interaction with SR (52). Ma etal. (53) proposed that pathogenic disruption of Disrupted-In-Schizophrenia-1 (DISC1)-SR binding can produce schizophrenia-like behavior by depleting D-serine levels. DISC1, the perturbation of which has been implicated in the pathophysiology of a number of mental disorders, including schizophrenia, major depressive disorder and bipolar disorder (54), binds to SR and stabilizes it. Using a mouse model of schizophrenia, Ma etal. (53) found that mutant DISC1 results in SR degradation and a D-serine deficiency. Svane etal. (55) administered D-serine to male and female rats and measured expression of nitric oxide synthase 1 adaptor protein (NOS1AP) (overexpressed in cortex of patients with schizophrenia), D2 receptors and DISC1 and found that it affects expression of these three genes in a sex-specific manner. Mustafa etal. (56) reported that NO S-nitrosylates SR, mediating feedback inhibition of formation of D-serine. Interaction of SR with Colga 3, a member of the Colgin subfamily A, may also be important since Colga
3 decreases the ubquitylation of SR, resulting in protection of the SR from degradation by the ubiquitin-proteasomal system (57). In their SR knockout mouse model (58), Balu and Coyle (59) observed reduced binding of cyclic adenosine monophosphate (cAMP)-responsive element binding (CREB) to the promoter regions of genes for three molecules implicated in the pathophysiology of schizophrenia, namely brain-derived neurotrophic factor (BDNF), microRNA-132, and Arc (60). In a recent review article, Wolosker has provided a useful table of regulators of SR activity and D-serine production (61).

In contrast to the distribution of SR and D-serine in the brain, DAAO is most abundant in the cerebellum and brain stem and at much lower concentrations in pre-frontal cortex, hippocampus, and substantia nigra $(13,35)$. It has been reported that the activity of DAAO in postmortem brain tissue from humans with schizophrenia is increased over that of controls $(62,63)$. Labrie etal. (41) found that genetic loss of DAAO reverses the schizophrenia-like phenotypes in mice displaying these behaviors because of a mutation in the NR1 subunit of the NMDA receptor. DAAO has been proposed to be regulated by the protein product of gene G72 (64-67), and variations in pLG72 have been associated with schizophrenia (68-72). There has been some discussion in the literature about the various functions of pLG72 in the brain and the molecular details of its interaction with DAAO, and these matters have been reviewed comprehensively by Pollegiani etal. (73). Hashimoto etal. (74) found that administering a DAAO inhibitor and Dserine simultaneously reduces prepulse inhibition seen in mice given dizocilpine, a non-competitive NMDA receptor antagonist. Other researchers have also co-administered DAAO inhibitors in conjunction with D-serine in preclinical studies and suggested that DAAO inhibitors could be useful in schizophrenia by reducing the required dose for $\mathrm{D}$-serine $(40,74-77)$.

\section{CLINICAL STUDIES WITH D-SERINE IN SCHIZOPHRENIA}

Levels of D-serine have been reported to be decreased in cerebrospinal fluid (CSF) and blood of schizophrenia patients $(18,78-84)$. Hashimoto etal. (84) reported that serum levels of D-serine in schizophrenia patients are lower than in controls, while $\mathrm{D}$-serine serum levels in mood-stabilized bipolar disorder patients are higher than those in controls, and they felt that this situation may reduce misdiagnosis between these disorders. Further, plasma levels of D-serine and the D-/L-serine ratio were increased significantly by clozapine in schizophrenia responders (85).

Clinical studies have been conducted in schizophrenia with D-serine alone and as an adjunct to antipsychotics. In a 4-week open-label study it was reported that D-serine at high dose (60 $\mathrm{mg} / \mathrm{kg} /$ day) resulted in improved neurocognitive function (86). The same group did follow-up studies on D-serine $(87,88)$. In one investigation they did a double-blind, placebo-controlled, parallel group randomized clinical trial on negative symptoms in at-risk individuals, and $\mathrm{D}$-serine was given at a dose of 60 $\mathrm{mg} / \mathrm{kg} /$ day in divided daily doses for 16 -weeks; it was concluded 
that D-serine should be useful for treatment of prodromal symptoms. In another double-blind study, they found that in schizophrenia patients treated with $\mathrm{D}$-serine at $60 \mathrm{mg} / \mathrm{kg} /$ day, there was a significant improvement in mismatch negativity (MMN) (auditory mismatch), a neurophysiological biomarker for NMDA receptor activity. Ermilov etal. (89) compared high dose ( $3 \mathrm{~g} /$ day) $\mathrm{D}$-serine with high dose olanzapine in treatmentresistant schizophrenia patients and concluded that a subgroup of patients could be maintained on D-serine. Interestingly, doses of $\mathrm{D}$-serine as high as $4 \mathrm{~g}$ per day have been reported to cause no adverse effects (18).

Several clinical studies with $\mathrm{D}$-serine have used it as a potential adjunctive drug (30-120 mg/kg/day) to antipsychotics. When added to non-clozapine antipsychotics in schizophrenia patients, D-serine has been reported to improve negative, positive, and cognitive symptoms (90-94) and to be relatively free of side effects even at high doses. A double-blind placebocontrolled study by Heresco-Levy etal. (91) examined the effect of supplemental D-serine in a group of patients stabilized on olanzapine or risperidone; at the end of 6-weeks of treatment, the D-serine intervention group demonstrated an improvement in cognitive, positive, and negative symptom domains and a significant alteration in depressive symptoms. Simultaneous measurement of serum amino acid concentrations did not detect any fluctuations of levels of any amino acids except D-serine. Meta-analyses of clinical trials comparing therapy with glycine modulatory site agonists, including $\mathrm{D}$-serine, concluded that all of these NMDA receptor agonists significantly ameliorate symptoms in multiple domains, including cognitive and affective symptoms, when added to atypical antipsychotics except for clozapine (92-94). However, negative studies on D-serine adjunctive therapy in schizophrenia have also been reported in the literature (95-98). There have been inconsistent results as to the therapeutic benefit of D-serine used at $30 \mathrm{mg} / \mathrm{kg} / \mathrm{d}$ to improve the negative and cognitive symptoms of the illness, with more consistent improvements found at doses of $60 \mathrm{mg} / \mathrm{kg} / \mathrm{d}$ or higher. The higher doses of D-serine may be needed to adequately potentiate NMDA receptor-mediated activation of the receptor and to also achieve adequate serum levels and a subsequent predictive increase in brain concentrations.

It is interesting that D-serine addition to clozapine does not increase the efficacy of clozapine (99); this may be because clozapine releases D-serine and glutamate (100) and may have agonist or partial agonist activity at NMDA receptors (99-101). It is also possible that individuals on clozapine do not respond to Dserine since they are more often older and/or treatment-resistant (99).

One of the problems of treating symptoms of schizophrenia with $\mathrm{D}$-serine is the fact that it is metabolized rapidly by DAAO, reducing its bioavailability and requiring administration of high doses, which could lead to peripheral neuropathies. There are also safety concerns that high concentrations of D-serine can cause potential nephrotoxicity related to its metabolism by DAAO as has been reported in rats that have developed acute tubular necrosis associated with higher doses of $\mathrm{D}$-serine (102). However, in clinical studies that have administered Dserine (4-weeks duration) in doses up to $120 \mathrm{mg} / \mathrm{kg} /$ day, there have been no significant side effects (including nephrotoxicity) reported (86). In this particular study, one patient who received $120 \mathrm{mg} / \mathrm{kg} / \mathrm{d}$ of $\mathrm{D}$-serine did show $2+$ proteinuria without glycosuria during the last week of treatment with no change in creatinine which completely resolved following the discontinuation of $\mathrm{D}$-serine. In a 16-week intervention study by the same group using $60 \mathrm{mg} / \mathrm{kg} / \mathrm{d}$ in clinically high-risk individuals, there were two patients who were discontinued in relation to abnormal renal values associated with treatment, with all other patients' renal abnormalities reported being resolved with continued treatment (87). The long-term side effects of D-serine beyond a 16-week treatment period are currently unknown. Additional studies that include longer time intervals should be conducted on this aspect of D-serine to ensure patient safety.

Studies on DAAO inhibitors indicate that they have limited effects on brain $\mathrm{D}$-serine levels in mice, although there is some disagreement in the literature on this [see Guercio and Panizzutti (103) for a discussion]. However, as mentioned in the above section on enzymes involved in metabolism of D-serine, several researchers have now co-administered DAAO inhibitors in conjunction with D-serine in preclinical studies, and their findings suggest that DAAO inhibitors could be useful clinically in schizophrenia for reducing the required dose of D-serine and thus also reducing potential side effects associated with the administration of high D-serine (74-77). Sodium benzoate, a frequently used food preservative, is also a DAAO inhibitor and has been reported to have beneficial effects in schizophrenia when added to antipsychotics (104).

\section{D-SERINE AND MAJOR DEPRESSIVE DISORDER}

As indicated above, there is now a strong body of evidence indicating the possible involvement of D-serine in the etiology of schizophrenia and suggesting its potential as an antipsychotic or an adjunct to existing antipsychotics. It has thus been very interesting to see research results indicating that it may also have antidepressant effects and/or be a potential biomarker for depression and response to the antidepressant effects of ketamine. The possible mechanisms involved in the antidepressant actions of D-serine are the subject of another paper in this volume and of a paper by Chan etal. (105) and will not be discussed here in detail.

As mentioned above, in clinical studies investigating D-serine as an adjunct to antipsychotics, improvement in the affective symptoms of these patients was also often observed (e.g., 8994). D-serine has now been reported to have antidepressant-like effects in rodent models of depression (105-107). Malkesman etal. (106) studied the behavioral effects in mice of a single, acute i.p. dose of D-serine in several tests of antidepressants, including the forced swim test, the female urine sniffing test following serotonin depletion and the learned helplessness paradigm and in mice lacking NR1 expression in excitatory neurons in the forebrain and found that $\mathrm{D}$-serine gave a positive response in each of the behavioral tests but that the same behavioral tests 
conducted in mice lacking NR1 expression did not respond to D-serine. Otte etal. (107) studied transgenic mice in which SR was overexpressed using paradigms of anxiety, depression, and cognition. These studies were done in the absence and presence of $\mathrm{D}$-serine in the drinking water. D-Serine administration resulted in a reversal of the findings in these tests, suggesting a reduced proneness toward depression-related behavior. Wei etal. (108) studied the effects of D-serine and ketamine on rats in the forced swim test and proposed that D-serine produces antidepressant-like effects through the same mechanisms as ketamine. Wang etal. (109) found that chronic social defeat stress (CSDS) in mice induces expression of the D-serine transporter through epigenetic activation and decreases levels of $\mathrm{D}$-serine in the hippocampus, leading to depression-like behavior.

The DAAO inhibitor sodium benzoate has been reported to have beneficial effects in a depressed patient (110) and acute administration of D-serine to healthy subjects has been reported to reduce subjective feelings of depression and anxiety as measured by Visual Analog Scales (111). Ishiwata etal. (112) reported that CSF levels of D-serine in depressed patients correlate negatively with severity of depression. In a comprehensive study on 70 depressed patients, Hashimoto etal. (113) found increased serum levels of both serine enantiomers compared to controls, while serum levels of glycine, glutamate, and glutamine did not differ between the depressed patients and controls. In contrast, Mitani etal. (114) had reported that plasma levels of $\mathrm{D}$ - and L-serine in major depressive disorder (MDD) patients were the same as those in healthy controls and levels of glutamate, glutamine, and glycine were higher in MDD patients than in controls. Hashimoto etal. (113) suggested that differences in severity of the depression between the two studies might account for some differences. Because of their findings of increased serum levels of D- and L-serine in MDD patients and a higher ratio of L-serine to glycine levels in the MDD patients, Hashimoto etal. (113) suggested abnormalities in synthesis and catabolism of serine enantiomers in MDD.

It is now well-accepted that intravenous administration of the NMDA receptor antagonist ketamine can produce a rapid improvement of symptoms of depression $(115,116)$. As noted above, several studies indicate that D-serine, an NMDA receptor coagonist, can also produce antidepressant effects. Malkesman etal. (106) state that the two drugs may activate common, convergent downstream targets, resulting in similar effects on protein expression and producing comparable changes in synaptic plasticity and dendritic remodeling. There are some interesting interactions between D-serine and ketamine reported. There is now evidence indicating that D-serine may be a predictive biomarker for antidepressant response to ketamine, with low plasma D-serine levels predicting a response to (R,S)-ketamine (117). Singh etal. (118) examined the effect of (R)- and (S)-ketamine on Alanine, Serine, Cysteine Transporter 2 (ASCT2)-mediated transport of Dserine in adrenal pheochromocytoma PC-12 and human neural astrocytoma $1321 \mathrm{~N} 1$ cells, and primary neuronal cells in culture and reported that (S)-ketamine decreased cellular export by selectively inhibiting ASCT2; the authors suggested that this interaction might represent a source of dissociative effects seen with (R,S)-ketamine. Singh etal. (118) also incubated PC-12 cells with a variety of ketamine metabolites and determined the $\mathrm{IC}_{50}$ values associated with attenuation of intracellular D-serine and proposed to use the findings to help in the design of more efficient modulators of Dserine.

\section{D-SERINE AND COGNITION}

Serious cognitive deficits can occur in a number of psychiatric disorders, including both schizophrenia and MDD. It has been reported that depletion of $\mathrm{D}$-serine levels in brain diminishes long-term potentiation (LTP), which is associated with learning and memory $(19,20)$. Genetic inactivation of SR in a mouse model and an acute stress model reduced brain levels of $\mathrm{D}$-serine and produced cognitive deficits (6, 119). Intraperitoneal injection of D-serine results in improved social memory in rats (120) and improved recognition and working memory in mice (121). In a rodent model study following development of offspring after prenatal maternal infection [using poly(I:C)], it was reported that supplementing offspring at juvenile and adolescent stages with $\mathrm{D}$-serine reduced cognitive deficits in adulthood (39). Panizzutti etal. (122) studied the association between serum D-serine levels and the results of intensive cognitive training in schizophrenia patients and found that in those patients receiving this training increased D-serine levels were positively correlated with improved global cognition and verbal learning, but such associations were not apparent with glycine. Despite the interesting findings mentioned above, $\mathrm{D}$-serine is not used clinically as a cognitive enhancer; in a recent review, Guercio and Panizzutti (103) have discussed various factors, including pharmacokinetics and possible side effects that must be studied in more detail in order to increase the efficacy of D-serine.

\section{SUMMARY}

In contrast to the usual situation with $\mathrm{D}$-amino acids, Dserine is abundant in the brain and appears to have important neuromodulatory roles. D-Serine is more potent than glycine as a coagonist at the NMDA receptor, has a regional distribution in the brain that is similar to that of NMDA receptors and appears to be more closely associated with synaptic NMDA receptors than glycine (which is more closely associated with non-synaptic NMDA receptors). There has been considerable controversy about the concentration and function of $\mathrm{D}$-serine in glia vs. neurons, but evidence in recent years indicates that neurons are more relevant to $\mathrm{D}$-serine action than originally thought. Synthesis and catabolism of D-serine are catalyzed by SR and DAAO, respectively. Regulation of these enzymes by various factors is quite complex. Decreased levels of Dserine in schizophrenia have been reported in several studies. Increasing D-serine levels in the brain may be an effective adjunct to antipsychotic treatment. D-Serine administered alone 
or in combination with usual antipsychotics may be useful in treating schizophrenia, but the high doses required may cause peripheral neuropathies, although these have not been evident thus far using doses up to $4 \mathrm{~g}$ /day. Nonetheless, more studies at longer time intervals should be conducted on this aspect of D-serine to ensure patient safety. Several studies have been conducted with $\mathrm{D}$-serine in combination with a DAAO inhibitor, with generally promising results obtained. Based on preclinical and clinical findings, D-serine also appears to have antidepressant properties. Several interesting pharmacodynamic and pharmacokinetic interactions between D-serine and ketamine have been reported, and, interestingly, evidence suggests that low plasma levels of $\mathrm{D}$-serine may predict positive antidepressant response to ketamine. Several animal model and clinical studies also indicate that $\mathrm{D}$-serine may be effective in reducing cognitive deficits, but that further study is necessary before considering it an effective cognitive enhancer for routine use in humans.

\section{REFERENCES}

1. Hashimoto A, Nishikawa T, Hayashi T, Fujii N, Harada K, Oka T, etal. The presence of free D-serine in rat brain. FEBS Lett. (1992) 296:33-6. doi: 10.1016/0014-5793(92)80397-Y

2. Hashimoto A, Nishikawa T, Konno R, Niwa A, Yasumura Y, Oka T, etal. Free $\mathrm{D}$-serine, $\mathrm{D}$-aspartate, and $\mathrm{D}$-alanine in central nervous system and serum in mutant mice lacking D-amino acid oxidase. Neurosci Lett. (1993) 152:33-6.

3. Hashimoto A, Oka T. Free D-aspartate and D-serine in the mammalian brain and periphery. Prog Neurobiol. (1997) 52:325-53. doi: 10.1016/S0301-0082(97)00019-1

4. Schell MJ, Brady RO Jr, Molliver ME, Snyder SH. D-Serine as a neuromodulator: regional and developmental localizations in rat brain glia resemble NMDA receptors. J Neurosci. (1997) 17:1604-15. doi: 10.1523/JNEUROSCI.17-05-01604.1997

5. Fuchs SA, Berger R, Klomp LW, de Koning TJ. D-Amino acids in the central nervous system in health and disease. Mol Genet Metab. (2005) 85:168-80. doi: 10.1016/j.ymgme.2005.03.003

6. Labrie V, Fukumura R, Rastogi A, Fick LJ, Wang W, Boutros PC, etal. Serine racemase is associated with schizophrenia susceptibility in humans and in a mouse model. Hum Mol Genet. (2009) 18:3227-43. doi: $10.1093 / \mathrm{hmg} / \mathrm{ddp} 261$

7. Kiriyama Y, Nochi H. D-Amino acids in the nervous and endocrine systems. Scientifica (2016) 2016:6494621. doi: 10.1155/2016/64 94621

8. Billard JM. D-Amino acids in brain neurotransmission and synaptic plasticity. Amino Acids (2012) 43:1851-60. doi: 10.1007/s00726-012-1346-3

9. Mothet J-P, Snyder SH. Brain D-amino acids: a novel class of neuromodulators. Amino Acids (2012) 43:1809-10. doi: 10.1007/s00726-012-1403-y

10. Errico F, Mothet JP, Usiello A. D-Aspartate: an endogenous NMDA receptor agonist enriched in the developing brain with potential involvement in schizophrenia. J Pharm Biomed Anal. (2015) 116:7-17. doi: 10.1016/j.jpba.2015.03.024

11. Genchi G. An overview on D-amino acids. Amino Acids (2017) 49:1521-33. doi: 10.1007/s00726-017-2459-5

12. Li Z, Xing Y, Guo X, Cui Y. Development of an UPLC-MS/MS method for simultaneous quantitation of $11 \mathrm{D}$-amino acids in different regions of rat brain: application to a study on the associations of D-amino acid concentration changes and Alzheimer's disease. J Chromatogr B Analyt Technol Biomed Life Sci. (2017) 1058:40-6. doi: 10.1016/j.jchromb.2017.05.011

13. Verrall L, Burnet PWJ, Betts JF, Harrison PJ. The neurobiology of D-amino acid oxidase and its involvement in schizophrenia. Mol Psychiatry (2010) 15:122-37. doi: 10.1038/mp.2009.99

\section{AUTHOR CONTRIBUTIONS}

GB and M-AM wrote the first draft. All authors (GB, M-AM, MK, RT, NDM, SMD) contributed to the literature search and the editing of the manuscript.

\section{FUNDING}

Funding for GB's research has been provided by CIHR (MOP86712) and the University of Alberta (FoMD TRIP research grant).

\section{ACKNOWLEDGMENTS}

The authors are grateful to the Canadian Institutes for Health Research, University of Alberta, and Alberta Health Services for research funding and to Trudy Valliere for assistance in typing this manuscript and Patricia Kent for preparing the figures.

14. Labrie V, Roder JC. The involvement of the NMDA receptor D-serine/glycine site in the pathophysiology and treatment of schizophrenia. Neurosci Behav Rev. (2010) 34:351-72. doi: 10.1016/j.neubiorev.2009.08.002

15. Balu DT, Basu AC, Corradi JP, Cacace AM, Coyle JT. The NMDA receptor co-agonists, D-serine and glycine, regulate neuronal dendritic architecture in the somatosensory cortex. Neurobiol Dis. (2012) 45:671-82. doi: 10.1016/j.nbd.2011.10.006

16. Hashimoto K, Malchow B, Falkai P, Schmitt A. Glutamate modulators as potential therapeutic drugs in schizophrenia and affective disorders. Eur Arch Psychiatry Clin Neurosci. (2013) 263:367-77. doi: 10.1007/s00406-013-0399-y

17. Tsai GE, Yang P, Chang Y-C, Chong MY. D-Alanine added to antipsychotics for the treatment of schizophrenia. Biol Psychiatry (2006) 59:230-4. doi: 10.1016/j.biopsych.2005.06.032

18. Durrant AR, Heresco-Levy U. D-Serine in neuropsychiatric disorders: new advances. Adv Psychiatry (2014) 2014:859735. doi: 10.1155/2014/859735

19. Balu DT, Coyle JT. The NMDA receptor 'glycine modulatory site' in schizophrenia: D-serine, glycine, and beyond. Curr Opin Pharmacol. (2015) 20:109-15. doi: 10.1016/j.coph.2014.12.004

20. Bardaweel SK, Alzweiri M, Ishaqat AA. D-Serine in neurobiology: CNS neurotransmission and neuromodulation. Can J Neurol Sci. (2014) 41:16476. doi: 10.1017/S031716710001653X

21. Wolosker H. NMDA receptor regulation by D-serine: new findings and perspectives. Mol Neurobiol. (2007) 36:152-64. doi: 10.1007/s12035-007-0038-6

22. Balu DT, Coyle JT. Neuronal D-serine regulates dendritic architecture in the somatosensory cortex. Neurosci Lett. (2012) 517:77-81. doi: 10.1016/j.neulet.2012.04.020

23. Kantrowitz JT, Epstein ML, Beggle O, Rohrig S, Lehrfeld JM, Revheim N, etal. Neurophysiological mechanisms of cortical plasticity impairments in schizophrenia and modulation by the NMDA receptor agonist D-serine. Brain (2016) 139:3281-95. doi: 10.1093/brain/aww262

24. Coyle JT, Tsai G, Goff D. Converging evidence of NMDA receptor hypofunction in the pathophysiology of schizophrenia. Ann NY Acad Sci. (2003) 1003:318-27. doi: 10.1196/annals.1300.020

25. Kantrowitz JT, Javitt DC. N-methyl-D-aspartate (NMDA) receptor dysfunction or dysregulation: the final common pathway on the road to schizophrenia? Brain Res Bull. (2010) 83:108-21. doi: 10.1016/j.brainresbull.2010.04.006

26. Lin $\mathrm{CH}$, Lane HY, Tsai GE. Glutamate signaling in the pathophysiology and therapy of schizophrenia. Pharmacol Biochem Behav. (2012) 100:665-77. doi: 10.1016/j.pbb.2011.03.023

27. Balu DT. The NMDA receptor and schizophrenia: from pathophysiology to treatment. Adv Pharmacol. (2016) 76:351-82. doi: 10.1016/bs.apha.2016.01.006 
28. Van Horn MR, Sild M, Ruthazer ES. D-Serine as a gliotransmitter and its role in brain development and disease. Front Cell Neurosci. (2013) 7:39. doi: 10.3389/fncel.2013.00039

29. Papouin T, Henneberger C, Rusakov DA, Oliet SHR. Astroglial versus neuronal D-serine: fact checking. Trends Neurosci. (2017) 40:517-20. doi: 10.1016/j.tins.2017.05.007

30. Wolosker H, Balu DT, Coyle JT. The rise and fall of the D-serinemediated gliotransmission hypothesis. Trends Neurosci. (2016) 39:712-21. doi: 10.1016/j.tins.2016.09.007

31. Matsui T, Sekiguchi M, Hashimoto A, Tomita U, Nishikawa T, Wada K. Functional comparison of D-serine and glycine in rodents: the effect on cloned NMDA receptors and the extracellular concentration. J Neurochem. (1995) 65:454-8. doi: 10.1046/j.1471-4159.1995.65010454.x

32. Shleper M, Kartvelishvily E, Wolosker H. D-Serine is the dominant endogenous coagonist for NMDA receptor neurotoxicity in organotypic hippocampal slices. J Neurosci. (2005) 25:9413-7. doi: 10.1523/JNEUROSCI.3190-05.2005

33. Papouin T, Ladépêche L, Ruel J, Sacchi S, Labasque M, Hanini $\mathrm{M}$, etal. Synaptic and extrasynaptic NMDA receptors are gated by different endogenous coagonists. Cell (2012) 150:633-46. doi: 10.1016/j.cell.2012.06.029

34. Hardingham GE, Hading H. Synaptic versus extrasynaptic NMDA receptor signaling: implications for neurodegenerative disorders. Nat Rev Neurosci. (2010) 11:682-96. doi: 10.1038/nrn2911

35. Labrie V, Wong AHC, Roder J. Contributions of the D-serine pathway to schizophrenia. Neuropharmacology (2012) 62:1484-503. doi: 10.1016/j.neuropharm.2011.01.030

36. Balu DT, Coyle JT. Chronic D-serine reverses arc expression and partially rescues dendritic abnormalities in a mouse model of NMDA receptor hypofunction. Neurochem Lett. (2014) 75:76-8. doi: 10.1016/j.neuint.2014.05.015

37. Anderson JD, Poulzet B. Spatial memory deficits induced by perinatal treatment of rats with PCP and reversal effect of D-serine. Neuropsychopharmacology (2004) 29:1080-90. doi: 10.1038/sj.npp.1300394

38. Hagiwara $H$, Iyo $M$, Hashimoto $K$. Neonatal disruption of serine racemase causes schizophrenia-like behavioral abnormalities in adulthood: clinical rescue by D-serine. PLoS ONE (2013) 8:e62438.28. doi: 10.1371/journal.pone.0062438

39. Fujita Y, Ishima T, Hashimoto K. Supplementation with D-serine prevents the onset of cognitive deficits in adult offspring after maternal immune activation. Sci Rep. (2016) 6:37261. doi: 10.1038/srep37261

40. Sershen H, Hashim A, Dunlop DS, Suckow RF, Cooper TB, Javitt DC. Modulating NMDA receptor function with $\mathrm{D}$-amino acid oxidase inhibitors: understanding functional activity in PCP-treated mouse model. Neurochem Res. (2016) 41:398-408. doi: 10.1007/s11064-016-1838-8

41. Labrie V, Wang W, LabrieBarger SW, Baker GB, Roder JC. Genetic loss of Damino acid oxidase activity reverses schizophrenia-like phenotypes in mice. Genes Brain Behav. (2010) 9:11-25. doi: 10.1111/j.1601-183X.2009.00529.x

42. Wolosker H, Blackshaw S, Snyder SH. Serine racemase: a glial enzyme synthesizing D-serine to regulate glutamate- $N$-methyl-D-aspartate neurotransmission. Proc Natl Acad Sci USA. (1999) 96:13409-14. doi: 10.1073/pnas.96.23.13409

43. Caldinelli L, Molla G, Bracci L, Lelli B, Pileri S, Cappelletti P, etal. Effect of ligand binding on human D-amino acid oxidase: implications for the development of new drugs for schizophrenia treatment. Protein Sci. (2010) 19:1500-12. doi: 10.1002/pro.429

44. Snell K, Fell DA. Metabolic control analysis of mammalian serine metabolism. Adv Enzyme Regul. (1990) 30:13-32. doi: 10.1016/0065-2571(90)90006-N

45. Coyle JT, Balu DT. The role of serine racemase in the pathophysiology of brain disorders. Adv Pharmacol. (2018) 82:35-56. doi: 10.1016/bs.apha.2017.10.002

46. Verrall L, Walker M, Rawlings N, Benzel I, Kew JN, Harrison PJ, etal. D-Amino acid oxidase and serine racemase in human brain: normal distribution and altered expression in schizophrenia. Eur J Neurosci. (2007) 26:1657-69. doi: 10.1111/j.1460-9568.2007.05769.x

47. Kim PM, Aizawa H, Kim PS, Huang AS, Wickramasinghe SR, Kashani $\mathrm{AH}$, etal. Serine racemase: activation by glutamate neurotransmission via glutamate receptor interacting protein and mediation of neuronal migration. Proc Nat Acad Sci USA. (2005) 6:2105-10. doi: 10.1073/pnas.0409723102

48. Mothet JP, Pollegioni L, Ouanounou G, Martineau M, Fissier P, Baux G. Glutamate receptor activation triggers a calcium-dependent and SNARE protein-dependent release of the gliotransmitter D-serine. Proc Natl Acad Sci USA. (2005) 102:5606-11. doi: 10.1073/pnas.04084 83102

49. Baumgart F, Manchen JM, Rodrigez-Crezpo I. Insights into the activation of brain serine racemase by the multi-PDZ domain glutamate receptor inter-acting protein, divalent cations and ATP. FEBS J. (2007) 274:4561-71. doi: 10.1111/j.1742-4658.2007.05986.x

50. Ma TM, Paul BC, Fu C, Hu S, Zhu H, Blackshaw S, etal. Serine racemase regulated by binding to stargazin and PSD-95: potential N-methyl-Daspartate-alpha-amino-3-hydroxy-5-methyl-4-isoxazolepropionic acid (NMDA-AMPA) glutamate neurotransmission cross-talk. J Biol Chem. (2014) 289:29631-41. doi: 10.1074/jbc.M114.571604

51. Lin H, Jocobi AA, Anderson SA, Lynch DR. D-Serine and serine racemase are associated with PSD-95 and glutamatergic synapse stability. Front Cell Neurosci. (2016) 10:34. doi: 10.3389/fncel.2016.00034

52. Fujii K, Maeda K, Hikida T, Mustafa AK, Balkissoon R, Xia J, etal. Serine racemase binds to PICK1: Potential relevance to schizophrenia. Mol Psychiatry (2006) 11:150-7. doi: 10.1038/sj.mp.4001776

53. Ma TM, Abazyan S, Abazyan B, Nomura J, Yang C, Seshadri S, etal. Pathogenic disruption of DISC1-serine racemase binding elicits schizophrenia-like behavior via D-serine depletion. Mol Psychiatry (2013) 18:557-67. doi: 10.1038/mp.2012.97

54. Lipina TV, Roder JC. Disrupted-in-Schizophrenia-1 (DISC1) interactome and mental disorders: impact of mouse models. Neurosci Biobehav Rev. (2014) 45:271-94. doi: 10.1016/j.neubiorev.2014.07.001

55. Svane KC, Asis EK, Omelchenko A, Kunnath AH, Brzustowicz LM, Silverstein SM, etal. D-Serine administration affects nitric oxide synthase 1 adaptor protein and DISC1 expression in sex-specific manner. Mol Cell Neurosci. (2018) 89:20-32. doi: 10.1016/j.mcn.2018.03.011

56. Mustafa AK, Kumar M, Selvakumar B, Ho GP, Ehmsen JT, Barrow RK, etal. Nitric oxide S-nitrosylates serine 56racemase, mediating feedback inhibition of D-serine formation. Proc Natl Acad Sci USA. (2007) 104:2950-5. doi: 10.1073/pnas.0611620104

57. Dumin E, Bendikov I, Foltyn VN, Misumi Y, Ikehara Y, Kartvelishvily E, etal. Modulation of $\mathrm{D}$-serine levels via ubiquitin-dependent proteasomal degradation of serine racemase. J Biol Chem. (2006) 281:20291-302. doi: 10.1074/jbc.M601971200

58. Balu DT, Li Y, Puhl MD, Benneyworth MA, Basu AC, Takagi S, etal. Multiple risk pathways for schizophrenia converge in serine racemase knockout mice, a mouse model of NMDA receptor hypofunction. Proc Natl Acad Sci USA. (2013) 110:E2400-9. doi: 10.1073/pnas.1304308110

59. Balu DT, Coyle JT. Altered CREB binding to activity-dependent genes in serine racemase deficient mice, a mouse model of schizophrenia. ACS Chem Neurosci. (2018) 9:2205-9. doi: 10.1021/acschemneuro.7b 00404

60. DeVito LM, Balu DT, Kanter BR, Lykken C, Basu AC, Coyle JT, etal. Serine racemase deletion disupts memory for order and alters cortical dendritic morpholgy. Genes Brain Behav. (2011) 10:210-22. doi: 10.1111/j.1601-183X.2010.00656.x

61. Wolosker H. The neurobiology of D-serine signaling. Adv Pharmacol. (2018) 82:325-48. doi: 10.1016/bs.apha.2017.08.010

62. Madiera C, Freitas ME, Vargas-Lopes C, Wolosker H, Panizzutti R. Increased D-amino acid oxidase (DAAO) activity in schizophrenia. Schizophr Res. (2008) 101:76-83. doi: 10.1016/j.schres.2008.02.002

63. Habl G, Zink M, Petrolanu G, Bauer M, Schneider-Azmann T, von Wilmsdorff $\mathrm{M}$, etal. Increased $\mathrm{D}$-amino acid oxidase expression in the bilateral hippocampal CA4 of schizophrenic patients: a postmortem study. J Neural Transm. (2009) 116:1657-65. doi: 10.1007/s00702-009-0312-z

64. Muller DJ, Zai CC, Shinkai T, Strauss J, Kennedy JL. Association between the DAOA/G72 gene and bipolar disorder and meta-analysis in bipolar disorder and schizophrenia. Bipolar Disord. (2011) 13:198-207. doi: 10.1111/j.1399-5618.2011.00905.x

65. Prata DP, Papagni SA, Mechelli A, Fu CH, Kambeitz J, Picchioni M, etal. Effect of D-amino acid oxidase activator (DAOA; G72) on brain 
function during verbal fluency. Hum Brain Mapp. (2012) 33:143-53. doi: $10.1002 / \mathrm{hbm} .21198$

66. Sacchi S, Cappelletti P, Giovannardi S, Pollegionni L. Evidence for the interaction of D-amino acid oxidase with pLG72 in a glial cell line. Mol Cell Neurosci. (2011) 48:20-8. doi: 10.1016/j.mcn.2011.06.001

67. Birolo L, Sacchi S, Smaldone G, Molla G, Leo G, Caldinelli L, etal. Regulating levels of the neuromodulator $\mathrm{D}$-serine in human brain: structural insight into pLG72 and D-amino acid oxidase interaction. FEBS J. (2016) 283:3353-70. doi: $10.1111 /$ febs. 13809

68. Detera-Wadleight SD, McMahon FJ. G72/G30 in schizophrenia and bipolar disorder: a review and meta-analysis. Biol Psychiatry (2006) 60:106-14. doi: 10.1016/j.biopsych.2006.01.019

69. Sacchi S, Bernasooni M, Martineau M, Mothet JP, Ruzzene M, Pilone MS, etal. pLG72 modulates intracellular D-serine levels through its interaction with D-amino acid oxidase: effect on schizophrenia susceptibility. J Biol Chem. (2008) 283:22244-56. doi: 10.1074/jbc.M709153200

70. Cappelletti P, Campomenosi P, Pollegioni L, Sacchi S. The degradation (by distinct pathways) of human D-amino acid oxidase and its interacting partner pLG72-two key proteins in D-serine catabolism in the brain. FEBS J. (2014) 281:708-23. doi: 10.1111/febs.12616

71. Chumakov I, Blumenfeld M, Guerassimenko O, Cavarec L, Palicio M, Abderrahim H, etal. Genetic and physiological data implicating the new human gene $\mathrm{G} 72$ and the gene for $\mathrm{D}$-amino acid oxidase in schizophrenia. Proc Natl Acad Sci USA. (2002) 99:13675-80. doi: 10.1073/pnas.1824 12499

72. Lin CH, Chang HT, Chen YJ, Lin CH, Huang CH, Tun R, etal. Distinctively higher plasma G72 protein levels in patients with schizophrenia than in the healthy individuals. Mol Psychiatry (2014) 19:636-7. doi: $10.1038 / \mathrm{mp} .2013 .80$

73. Pollegioni L, Plubelli L, Molla G, Rosini E. D-Amino acid oxidasepLG72 interaction and D-serine modulation. Front Mol Biosci. (2018) 5:3. doi: $10.3389 / \mathrm{fmolb} .2018 .00003$

74. Hashimoto K, Fujita Y, Horio M, Kunitachi S, Iyo M, Ferraris D, etal. Co-administration of a D-amino acid oxidase inhibitor potentiates the efficacy of D-serine in attenuating prepulse inhibition deficits after administration of dizocilpine. Biol Psychiatry (2009) 65:1103-6. doi: 10.1016/j.biopsych.2009.01.002

75. Ferraris D, Duvall B, Ko Y-S, Thomas AG, Rojas C, Majer P, etal. Synthesis and biological evaluation of D-amino acid oxidase inhibitors. J Med Chem. (2008) 51:3357-9. doi: 10.1021/jm800200u

76. Ferraris DV, Tsukamoto T. Recent advances in the discovery of D-amino acid oxidase inhibitors and their therapeutic utility in schizophrenia. Curr Pharm Des. (2011) 17:103-11. doi: 10.2174/138161211795049633

77. Sacchi S, Rosini E, Pollegioni L, Molla G. D-Amino acid oxidase inhibitors as a novel class of drugs for schizophrenia therapy. Curr Pharm Des. (2013) 19:2499-511. doi: 10.2174/1381612811319140002

78. Hashimoto K, Fukushima T, Shimizu E, Kamotsu N, Watanabe H, Shinoda N, etal. Decreased serum levels of D-serine in patients with schizophrenia: evidence in support of the N-methyl-D-aspartate receptor hypofunction hypothesis of schizophrenia. Arch Gen Psychiatry (2003) 60:572-6. doi: 10.1001/archpsyc.60.6.572

79. Hashimoto K, Engberg G. Shimizu E, Nordin C, Lindstrom LH, Iyo M. Reduced D-serine to total serine ratio in the cerebrospoinal fluid of drug naive schizophrenic patients. Prog Neuropsychopharmacol Biol Psychiatry (2005)29:767-9. doi: 10.1016/j.pnpbp.2005.04.023

80. Bendikov I, Nadri C, Amar S, Panizzutti R, De Miranda J, Wolosker $\mathrm{H}$, etal. A CSF and postmortem brain study of D-serine metabolic parameters in schizophrenia. Schizophr Res. (2007) 90:41-51. doi: 10.1016/j.schres.2006.10.010

81. Ohnuma T, Sakai Y, Maeshima H, Hatano T, Hanzawa R, Abe S. Changes in plasma glycine, L-serine and D-serine levels in patients with schizophrenia as their clinical symptoms improve: results from the Juntendo University Schizophrenia Projects (JUSP). Prog Neuropsychopharmacol Biol Psychiatry (2008) 32:1905-12. doi: 10.1016/j.pnpbp.2008.07.022

82. Calcia, MA, Madeira C, Alheira FV, Silva TC, Tannos FM, VargasLopes C, etal. Plasma levels of D-serine in Brazilian individuals with schizophrenia. Schizophr Res. (2012) 142:83-7. doi: 10.1016/j.schres.2012. 09.014
83. Cho SE, Na K-S, Cho S-J, Kang SG. Low D-serine levels in schizophrenia: a systematic review and meta-analysis. Neurosci Lett. (2016) 634:42-51. doi: 10.1016/j.neulet.2016.10.006

84. Hashimoto K. Serine enantiomers as diagnostic biomarkers in schizophrenia and bipolar disorder. Eur Arch Psychiatry Clin Neurosci. (2016) 266:83-5. doi: 10.1007/s00406-015-0602-4

85. Yamamori H, Hashimoto R, Fujita Y, Numata S, Yasuda Y, Fujimoto M, etal. Changes in plasma D-serine, L-serine, and glycine levels in treatmentresistant schizophrenia before and after clozapine treatment. Neurosci Lett. (2014) 582:93-8. doi: 10.1016/j.neulet.2014.08.052

86. Kantrowitz JT, Malhotra AK, Cornblatt B, Silipo G, Ball A, Suckow RF. High dose D-serine in the treatment of schizophrenia. Schizophr Res. (2010) 121:125-30. doi: 10.1016/j.schres.2010.05.012

87. Kantrowitz JT, Woods SW, Petkova E, Cornblatt B, Corcoran CM, Chen $\mathrm{H}$, etal. D-Serine for the treatment of negative symptoms in individuals at clinical high risk of schizophrenia: a pilot, double-blind, placebocontrolled, randomized parallel group mechanistic proof-of-concept trial. Lancet Psychiatry (2015) 2:403-12. doi: 10.1016/S2215-0366(15)00098-X

88. Kantrowitz JT, Epstein ML, Lee M, Lehrfeld N, Nolan KA, Shope C, etal. Improvement in mismatch negativity generation during D-serine treatment in schizophrenia: correlation with symptoms. Schizophr Res. (2018) 191:709. doi: 10.1016/j.schres.2017.02.027

89. Ermilov M, Gelfin E, Levin R, Lichtenberg P, Hashimoto K, Havitt DC, etal. A pilot double-blind comparison of D-serine and high-dose olanzapine in treatment-resistant patients with schizophrenia. Schizophr Res. (2013) 150:604-5. doi: 10.1016/j.schres.2013.09.018

90. Tsai G, Yang P, Chung LC, Lange N, Coyle JT. D-serine added to antipsychotics for the treatment of schizophrenia. Biol Psychiatry (1998) 44:1081-9.

91. Heresco-Levy U, Javitt DC, Ebstein R, Vass A, Lichtenberg P, Bar G, etal. DSerine efficacy as add-on pharmacotherapy to risperidone and olanzapine for treatment-refractory schizophrenia. Biol Psychiatry (2005) 57:577-85. doi: 10.1016/j.biopsych.2004.12.037

92. Tsai, GE, Lin PY. Strategies to enhance N-methyl-D-aspartate receptor -mediated neurotransmission in schizophrenia, a critical review and meta-analysis. Curr Pharm Design (2010) 16:522-37. doi: 10.2174/138161210790361452

93. Choi KH, Wykes T, Kurtz MM. Adjunctive pharmacotherapy for cognitive deficits in schizophrenia: meta-analytical investigation of efficacy. $\mathrm{Br} \mathrm{J}$ Psychiatry (2013) 203:172-8. doi: 10.1192/bjp.bp.111.107359

94. Singh SP, Singh V. Meta-analysis of the efficacy of adjunctive NMDA receptor modulators in chronic schizophrenia. CNS Drugs (2011) 25:859-85. doi: 10.2165/11586650-000000000-00000

95. Lane H-Y, Chang Y-C, Liu Y-C, Chiu C-C, Tsai GE. Sarcosine or D-serine add-on treatment for acute exacerbation of schizophrenia: a randomized, double-blind, placebo-controlled study. Arch Gen Psychiatry (2005) 62:1196204. doi: $10.1001 /$ archpsyc.62.11.1196

96. Weiser M, Heresco-Levy U, Davidson M, Javitt DC, Werbeloff N, Gershon AA, etal. A multicenter, add-on randomized controlled trial of low-dose D-serine for negative and cognitive symptoms of schizophrenia. J Clin Psychiatry (2012) 73:e728-34. doi: 10.4088/JCP.11m07031

97. Nunes EA, MacKenzie EM, Rossolatos D, Perez-Parada J, Baker GB, Dursun SM. D-Serine and schizophrenia: an update. Expert Rev Neurother. (2012) 12:801-12. doi: 10.1586/ern. 12.65

98. Iwata Y, Nakajima S, Suzuki T, Keefe RS, Plitman E, Chung JK, etal. Effects of glutamate positive modulators on cognitive deficits in schizophrenia: a systematic review and meta-analysis of double-blind randomized controlled trials. Mol Psychiatry (2015) 20:1151-60. doi: 10.1038/mp.2015.68

99. Tsai GE, Yang P, Chung LC, Tsai IC, Tsai CW, Coyle JT. D-serine added to clozapine for the treatment of schizophrenia. Am J Psychiatry (1999) 156:1822-5.

100. Tanahashi S, Yamamura S, Nakagawa M, Motomura E, Okada M. Clozapine, but not haloperidol, enhances glial $\mathrm{D}$-serine and L-glutamate release in rat frontal cortex and primary cultured astrocytes. Br J Pharmacol. (2012) 165:1543-55. doi: 10.1111/j.1476-5381.2011.01638.x

101. Chen L, Yang CR. Interaction of dopamine D1 and NMDA receptors mediates acute clozapine potentiation of glutamate EPSPs in rat prefrontal cortex. J Neurophysiol. (2002) 87:2324-36. doi: 10.1152/jn.2002.87.5.2324 
102. Carone FA, Ganote CE. D-serine nephrotoxicity. The nature of proteinuria, glucosuria, and aminoaciduria in acute tubular necrosis. Arch Pathol. (1975) 12:658-62.

103. Guercio GD, Panizzutti R. Potential and challenges for the clinical use of D-serine as a cognitive enhancer. Front Psychiatry (2018) 9:14. doi: 10.3389/fpsyt.2018.00014

104. Lane HY, Lin CH, Green MF, Hellemann G, Huang CC, Chen PW, etal. Add-on treatment of benzoate for schizophrenia: a randomized, doubleblind, placebo-controlled trial of a $\mathrm{D}$-amino acid oxidase inhibitor. JAMA Psychiatry (2013) 70:1267-75. doi: 10.1001/jamapsychiatry.2013.2159

105. Chan SY, Matthews E, Burnet PWJ. On or off?: modulating the N-methylD-aspartate receptor in major depression. Front Mol Neurosci. (2017) 9:169. doi: 10.3389/fnmol.2016.00169

106. Malkesman O, Austin DR, Tragon T, Wang G, Rompala G, Hamidi $\mathrm{AB}$, etal. Acute $\mathrm{D}$-serine treatment produces antidepressant-like effects in rodents. Int J Neuropsychopharmacol. (2012) 15:1135-48. doi: $10.1017 /$ S1461145711001386

107. Otte DM, Barcena de Arellano ML, Bilkei-Gorzo A, Albayram O, Imbeault $\mathrm{S}$, Jeung $\mathrm{H}$, etal. Effects of chronic D-serine elevation on animal models of depression and anxiety-related behavior. PLoS ONE (2013) 8:e67131. doi: 10.1371/journal.pone.0067131

108. Wei IH, Chen KT, Tsai MH, Wu CH, Lane HY, Huang CC. Acute amino acid D-serine administration, similar to ketamine, produces antidepressant-like effects through identical mechanisms. J Agric Food Chem. (2017) 65:10792803. doi: 10.1021/acs.jafc.7b04217

109. Wang J, Zhang K, Chen X, Liu X, Teng H, Zhao M, etal. Epigenetic activation of ASCT2 in the hippocampus contributes to depression-like behavior by regulating D-serine in mice. Front Mol Neurosci. (2017) 10:139. doi: 10.3389/fnmol.2017.00139

110. Lai C-H, Lane H-Y, Tsai GE. Clinical and cerebral volumetric effects of sodium benzoate, a D-amino acid oxidase inhibitor, in a drugnave patient with major depression. Biol Psychiatry (2012) 71:e9-10. doi: 10.1016/j.biopsych.2011.10.034

111. Levin R, Dor-Abarbanel AE, Edelman S, Durrant AR, Hashimoto K, Javitt DC, etal. Behavioral and cognitive effects of the N-methyl-D-aspartate receptor co-agonist $\mathrm{D}$-serine and healthy humans: initial findings. J Psychiatr Res. (2015) 61:188-95. doi: 10.1016/j.jpsychires.2014.12.007

112. Ishiwata S, Hattori K, Sasayama D, Teraishi T, Miyakawa T, Yokota Y, etal. Cerebrospinal fluid D-serine concentrations in major depressive disorder negatively correlate with depression severity. J Affect Disord. (2018) 226:15562. doi: 10.1016/j.jad.2017.09.035

113. Hashimoto K, Yoshida T, Ishikawa M, Fujita Y, Niitsu T, Nakazato M, etal. Increased serum levels of serine enantiomers in patients with depression. Acta Neuropsychiatr. (2016) 28:173-8. doi: 10.1017/neu.2015.59
114. Mitani H, Shirayama Y, Yamada T, Maeda K, Ashby CR Jr, Kawahara R. Correlation between plasma levels of glutamate, alanine and serine with severity of depression. Prog Neuropsychopharmacol Biol Psychiatry (2006) 30:1155-8. doi: 10.1016/j.pnpbp.2006.03.036

115. Zarate CA Jr, Niciu MJ. Ketamine for depression: evidence, challenges and promise. World Psychiatry (2015) 14:348-50. doi: 10.1002/wps.20269

116. Krystal JH, Sanacora G, Duman RS. Rapid-acting glutamatergic antidepressants: the path to ketamine and beyond. Biol Psychiatry (2013) 73:1133-41. doi: 10.1016/j.biopsych.2013.03.026

117. Moaddel R, Luckenbaugh DA, Xie Y, Villaseñor A, Brutsche NE, Machado-Vieira $\mathrm{R}$, etal. D-serine plasma concentration is a potential biomarker of $(\mathrm{R}, \mathrm{S})$-ketamine antidepressant response in subjects with treatment-resistant depression. Psychopharmacology (2015) 232:399-409. doi: 10.1007/s00213-014-3669-0

118. Singh NS, Bernier M, Camandola S, Khadeer MA, Moaddel R, Mattson MP, etal. Enantioselective inhibition of D-serine transport by (S)-ketamine. Br J Pharmacol. (2015) 172:4546-59. doi: 10.1111/bph.13239

119. Guercio GD, Bevictori I, Vargas-Lopes C, Madeira C, Oliveira A, Carvalho VF, etal. D-serine prevents cognitive deficits induced by acute stress. Neuropharmacology (2014) 861:1-8. doi: 10.1016/j.neuropharm.2014.0 6.021

120. Shimazaki T, Kaku A, Chaki S. D-Serine and a glycine transporter-1 inhibitor enhance social memory in rats. Psychopharmacology (2010) 209:263-70. doi: 10.1007/s00213-010-1794-y

121. Bado P, Madeira C, Vargas-Lopes C, Moulin TC, Wastlewska-Sampaio AP, Maretti L, etal. Effects of low-dose D-serine on recognition and working memory in mice. Psychopharmacology (2011) 218:461-70. doi: 10.1007/s00213-011-2330-4

122. Panizzutti R, Fisher M, Garrett C, Man WH, Sena W, Madeira C, etal. Association between increased serum $\mathrm{D}$-serine and cognitive gains induced by intensive cognitive training in schizophrenia. Schizophr Res. (2018) doi: 10.1016/j.schres.2018.04.011. [Epub ahead of print].

Conflict of Interest Statement: The authors declare that the research was conducted in the absence of any commercial or financial relationships that could be construed as a potential conflict of interest.

Copyright (c) 2019 MacKay, Kravtsenyuk, Thomas, Mitchell, Dursun and Baker. This is an open-access article distributed under the terms of the Creative Commons Attribution License (CC BY). The use, distribution or reproduction in other forums is permitted, provided the original author(s) and the copyright owner(s) are credited and that the original publication in this journal is cited, in accordance with accepted academic practice. No use, distribution or reproduction is permitted which does not comply with these terms. 